\title{
Non-coding RNAs that regulate the Wnt/ $\beta$-catenin signaling pathway in gastric cancer: Good cop, bad cop? (Review)
}

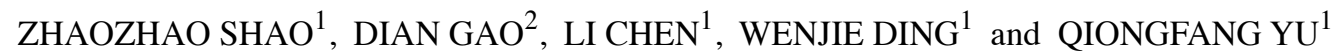 \\ ${ }^{1}$ Department of Gastroenterology and Hepatology, Second Affiliated Hospital of Nanchang University; \\ ${ }^{2}$ Department of Pathogen Biology and Immunology, Medical College of Nanchang University, \\ Nanchang, Jiangxi 330006, P.R. China
}

Received April 1, 2020; Accepted July 13, 2020

DOI: $10.3892 /$ or.2020.7705

\begin{abstract}
Gastric cancer (GC) is one of the most common causes of cancer-related mortality worldwide. Despite remarkable progress in the diagnosis and treatment of GC, a large number of cases are diagnosed as advanced GC, and treatment failure occurs. Emerging evidence has shown that non-coding RNAs (ncRNAs), especially microRNAs (miRNAs) and long non-coding RNAs (lncRNAs), play a vital role in the tumorigenesis and development of GC. Moreover, the pathogenesis of GC is closely related to aberrant activation of the Wnt (Wingless-type MMTV integration site family) signaling pathway. ncRNAs serve as potential novel biomarkers in the clinical examination, prognosis and therapeutic targeting of GC. Furthermore, dysregulation of ncRNAs has been demonstrated to affect tumor initiation, epithelial-mesenchymal transition (EMT), angiogenesis, tumor development, invasion, metastasis and resistance to therapy via the $\mathrm{Wnt} / \beta$-catenin signaling pathway. This review focuses on the role of ncRNAs in modulating the $\mathrm{Wnt} / \beta$-catenin signaling pathway in the pathogenesis of $\mathrm{GC}$, which may provide a reference for the clinical diagnosis and treatment of GC.
\end{abstract}

\section{Contents}

1. Introduction

2. Search methods

3. Wnt pathway

4. Non-coding RNAs and gastric cancer

5. IncRNAs

6. MicroRNAs

7. Conclusions and perspectives

Correspondence to: $\mathrm{Dr}$ Qiongfang Yu, Department of Gastroenterology and Hepatology, Second Affiliated Hospital of Nanchang University, 1 Minde Road, Nanchang, Jiangxi 330006, P.R. China

E-mail: qiongfangyu@yeah.net

Key words: non-coding RNAs, Wnt//-catenin signaling pathway, gastric cancer, pathogenesis, biomarker

\section{Introduction}

Globally, gastric cancer (GC) is the leading cause of cancer-related mortality and one of the most common types of cancers (1). The number of newly discovered GC cases worldwide reached over 1,000,000 in 2018, with 783,000 GC-related deaths, making it the fifth most commonly diagnosed cancer (2). East Asia is one of the major regions with a high incidence of GC (3). For example, GC ranks as the second leading cause of cancer-related death in China (4). Despite a large amount of progress in diagnosis and therapeutic strategies, the overall survival of GC patients remains unsatisfactory (5). Furthermore, due to the lack of sensitive predictive markers at an early stage and the lack of specific symptoms, the majority of GC patients are diagnosed with advanced GC or metastasis (6). Therefore, it is urgent to explore the molecular mechanism and critical signaling pathways underlying the initiation and progression of GC.

In recent decades, numerous studies have demonstrated that non-coding RNAs (ncRNAs), primarily microRNAs (miRNAs) and long non-coding RNAs (lncRNAs), are closely related to every stage of GC, including tumorigenesis, growth, development, apoptosis, invasion, metastasis, and drug resistance (7). The role of ncRNAs as promising biomarkers in the diagnosis of GC has also been deeply studied (8). It is worth noting that activation of the wingless-type MMTV integration site family (Wnt)/ $\beta$-catenin signaling pathway has a vital role in a variety of cancers, such as breast cancer (9), colon cancer (10) and liver cancer (11). Indeed, continual activation of $\mathrm{Wnt} / \beta$-catenin signaling pathway is closely related to the carcinogenesis of GC (12-14). Thus, efforts to further understand the mechanism by which ncRNAs modulate the Wnt/ $\beta$-catenin signaling pathway may provide early effective diagnosis and potential novel therapeutic strategies for GC. Therefore, in this review, we summarize the role of ncRNAs in regulating the $\mathrm{Wnt} / \beta$-catenin signaling pathway in the pathogenesis of GC.

\section{Search methods}

In the current main literature databases, PubMed is the most widely used premier bibliographic database in the life sciences and biomedicine fields. In addition, Web of Science is the 
largest comprehensive academic information resource with the most disciplines in the world. Therefore, we identify eligible studies using the following terms: ' $\beta$-catenin', 'Wnt', 'gastric cancer' and 'non-coding RNA' in the PubMed and Web of Science databases. The search began on February 1, 2020, and the last retrieval was on March 15, 2020. The citation lists associated with the studies were used to identify additional eligible studies. Reviews and bibliographies were also manually inspected to identify related articles. The role of ncRNAs in regulating the $\mathrm{Wnt} / \beta$-catenin signaling pathway in the pathogenesis of GC was analyzed.

\section{Wnt pathway}

Classification. The Wnt signaling pathway is a highly conserved extracellular signal transduction pathway that is triggered by the binding of the ligand protein Wnt to its membrane protein receptor. In 1982, the Wnt gene was first discovered in mouse breast cancer. As activation of this gene relies on the insertion of mouse breast cancer-associated viral genes, it was named 'Intl' (15). Subsequent studies discovered that the Intl gene plays an essential role in the normal embryonic development of mice and that its function is similar to that of the Wingless gene of Drosophila, which controls axial development of the fruit fly embryo. Due to the similarity between these two genes, Wingless and Intl were combined and named 'Wnt' (16-19).

The Wnt pathway is mainly divided into three pathways: i) The canonical Wnt or $\beta$-catenin dependent pathway, which activates expression of target genes in nucleus planar cells; ii) the polarity (PCP) pathway, which participates in Jun $\mathrm{N}$-terminal kinase (JNK) activation and cytoskeletal rearrangement; and iii) the $\mathrm{Wnt} / \mathrm{Ca}^{2+}$ pathway, which participates in activation of phospholipase $\mathrm{C}$ (PLC) and protein kinase $\mathrm{C}$ (PKC) (20-23). The last two pathways together are called the 'non-classical' or ' $\beta$-catenin-independent' pathways (24).

Wnt/ $\beta$-catenin signaling pathway and $G C$. The Wnt/ $\beta$-catenin signaling pathway is a classical Wnt pathway by which $\beta$-catenin accumulates in the cytoplasm and eventually translocates to the nucleus and coactivates transcription with TCF/LEF (T cytokine/lymphoid enhancer factor) family members (21). The Wnt signal is induced when the Wnt protein binds to a cysteine-rich domain of the N-terminal of the Frizzled (Fz) family of receptors (25). Following gene transduction and TCF/LEF transcription, the factor induces transcription of the target gene that ultimately acts on Wnt, inducing subsequent cellular responses (Fig. 1) $(26,27)$.

Among these Wnt signaling pathways, the Wnt/ $\beta$-catenin signaling pathway is highly evolutionarily conserved. It is involved in the pathogenesis of gastric carcinoma (28). According to statistics, activation of $\mathrm{Wnt} / \beta$-catenin signaling pathway can be found in $\sim 30-50 \%$ of GC tissues (29).

\section{Non-coding RNAs and gastric cancer}

Non-coding RNAs (ncRNAs) are a group of RNA transcribed from the genome that do not have protein-coding functions (30). In the past, most ncRNAs were considered 'evolutionary junk', but developments in molecular biology suggest that mutation or aberrant expression of ncRNAs has a huge impact on the occurrence and development of diseases, including cancers (31). Recently, ncRNAs have attracted widespread attention. It has also been confirmed that abnormal expression of miRNAs strongly contributes to the initiation and development of carcinoma (32). IncRNAs exert potent tumor-suppressive or -promoting effects on the pathogenic processes underlying GC tumorigenesis and progression (33). In addition, miRNAs have been verified to have deep connections to the occurrence, development, proliferation, metastasis, and invasion of GC (33-37).

\section{IncRNAs}

lncRNAs act on members of the Wnt/ $\beta$-catenin signaling pathway to regulate $G C$. Glycogen synthase kinase- $3 \beta$ (GSK-3 $\beta$ ) is an evolutionarily highly conserved serine/threonine kinase that is ubiquitous in mammalian eukaryotic cells. It acts on many signaling proteins, structural proteins and transcription factors, regulating cell differentiation, proliferation, survival and apoptosis $(38,39)$. One study revealed that lncRNA LINC01225 activates the Wnt/ $\beta$-catenin signaling pathway mainly by inhibiting $G S K-3 \beta$ to promote the proliferation, migration, invasion and EMT of GC (40). In another study, $G S K-3 \beta$ was identified as a target gene of lncRNA small nucleolar RNA host gene 20 (SNHG20) in GC cells. Promoting expression of IncRNA SNHG20 suppresses that of $G S K-3 \beta$ to activate the $\mathrm{Wnt} / \beta$-catenin signaling pathway in GC (41).

In addition to activating Wnt/ $\beta$-catenin signaling pathway, some lncRNAs play a completely opposite role. For instance, upregulation of lncRNA GATA6 antisense RNA 1 (GATA6-AS1) suppresses the Wnt/ $\beta$-catenin signaling pathway by recruiting enhancer of Zeste homolog 2 (EZH2) to the Frizzled family receptor 4 (FZD4) promoter region, enhancing $\mathrm{H} 3 \mathrm{~K} 27 \mathrm{me} 3$ and downregulating expression of FZD4, both of which reduce the occurrence, development, and invasion of GC (42).

IncRNAs regulate $G C$ by inhibiting mediators of the Wnt/ $\beta$-catenin signaling pathway. Desmoplakin (DSP), a class of proteins found in desmosomes, can decrease the level of $\beta$-catenin both in the cytoplasm and nucleus. Upregulation of lncRNA MIR4435-2HG diminishes the activity of DSP, thus promoting GC growth and metastasis (43). In addition, knockdown of lncRNA zinc finger antisense (ZFAS)1 increases expression of miR-200b, which targets Wnt1 to inhibit the induction of cell proliferation, cell cycle progression and activation of $\mathrm{Wnt} / \beta$-catenin signaling pathway in GC $(44,45)$.

Furthermore, lncRNAs act as tumor suppressors by altering Wnt/ $\beta$-catenin signaling pathway via their mediators. IncRNA LINC01314 is expressed at low levels in GC tissue, and enhancing its expression was found to inhibit GC tumor growth, invasion and migration in nude mice by directly suppressing the Wnt/ $\beta$-catenin signaling pathway via downregulation of kallikrein 4 (KLK4) (46).

IncRNAs act as ceRNAs to regulate $G C$ via the Wnt/ $\beta$-catenin signaling pathway. Competing endogenous RNA (ceRNA) refers to a new mechanism of interaction between RNAs; that is, ceRNA binds to miRNA via microRNA response 

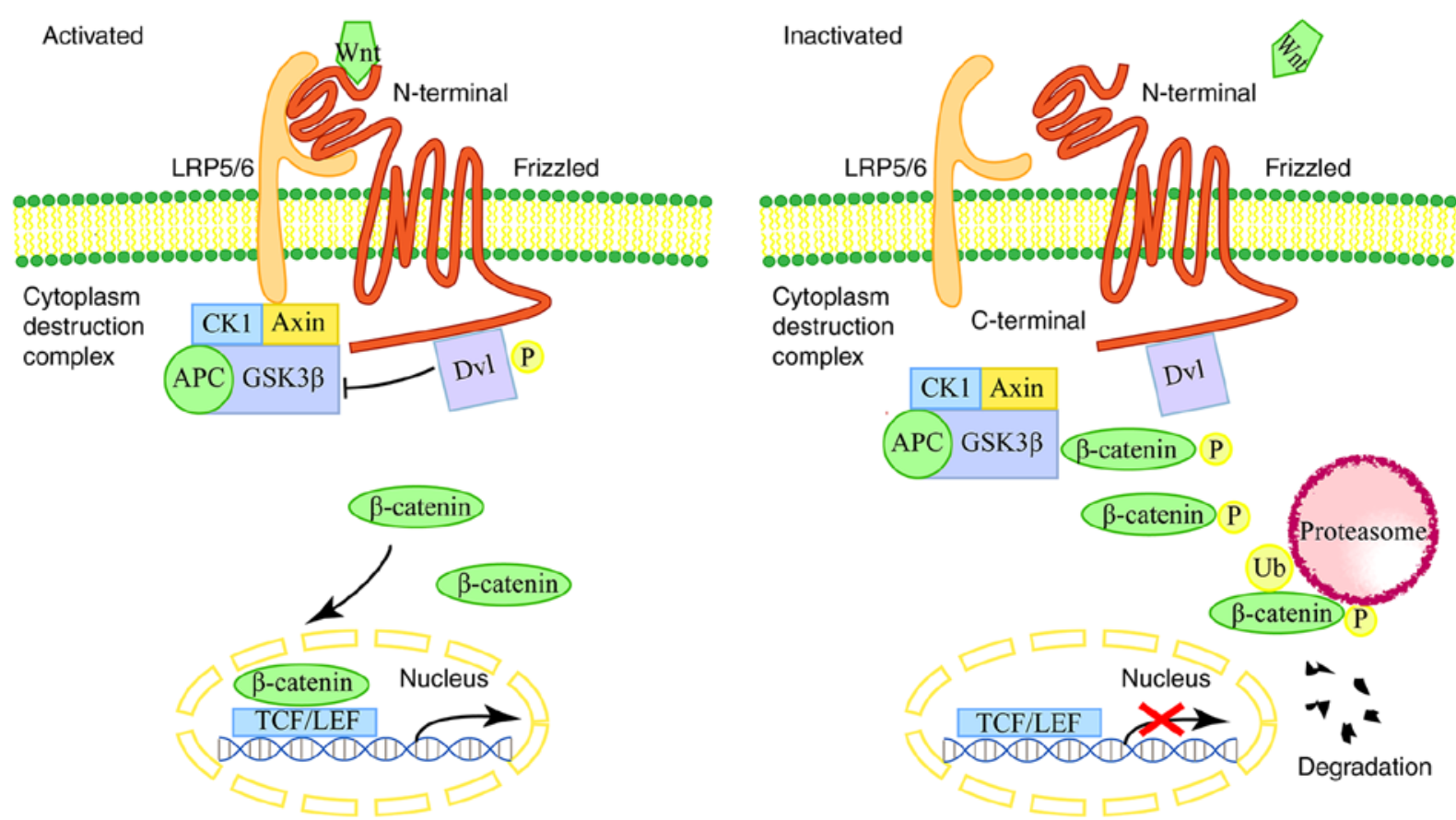

Figure 1. The Wnt//-catenin signaling pathway. When the signal is activated, the Wnt ligand binds to the Frizzled (Fz) receptor and coreceptor lipoprotein receptor-related protein (LRP 5/6), causing adaptor protein Dishevelled (Dvl) to inhibit the destruction complex, which is composed of adenoma colon polyp (APC), glycogen synthase kinase $3 \beta$ (GSK3 $\beta$ ), axin and casein kinase 1 (CK1). This allows $\beta$-catenin to accumulate and translocate to the nucleus and combine with T-cytokine (TCF)/lymphocyte enhancer-binding factor (LEF) transcription factors for target gene expression. In contrast, when the signal is

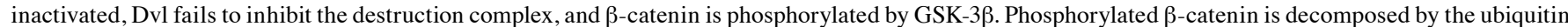
(Ub)-proteasome system.

elements (MERs) to regulate target gene expression $(47,48)$. A large number of studies have demonstrated that ceRNAs may be inextricably linked to multiple cancers, including GC (49-51).

lncRNA Homeobox A11 (HOXA11) antisense RNA (HOXA11-AS) serves as a ceRNA by sponging miR-148a, which deactivates the Wnt/ $\beta$-catenin signaling pathway by directly targeting Wnt1. Thus, IncRNA HOXA11-AS promotes the migration and invasion of GC cells, leading to a poor clinical survival rate (52). Consistent with this finding, lncRNA LIN01606 was verified to increase expression of Wnt3a by acting as a ceRNA of miR-423-5p, thereby promoting cell migration and invasion of GC though activation of the Wnt/ $\beta$-catenin signaling pathway (53).

In addition, some lncRNAs can serve as tumor suppressors in GC. LINC01133 regulates adenoma colon polyp (APC) by acting as a ceRNA of miR-106a-3p. LINC01133 also inhibits nuclear accumulation of the $\beta$-catenin protein by inhibiting miR-106a-3p and promoting APC expression to inhibit activation of Wnt/ $\beta$-catenin signaling pathway, thus suppressing EMT and metastasis in GC (54).

Similarly, lncRNA TOB1 antisense RNA 1 (TOB1-AS1) functions as a ceRNA of miR-23a to abolish its inhibitory effector on neuraminidase 1 (NEU1), promoting apoptosis and inhibiting the metastasis of GC via the Wnt/ $\beta$-catenin signaling pathway (55).

\section{MicroRNAs}

miRNAs act on members of the Wnt/ $\beta$-catenin signaling pathway to regulate $G C$. In addition to participating in
Wnt/ $\beta$-catenin signaling pathway regulation via lncRNA-mediated mechanisms, some miRNAs directly exert regulatory effects on the Wnt/ $\beta$-catenin signaling pathway in GC. miR-214 was discovered to downregulate expression of GSK-3 $\beta$. As a downstream gene of $G S K-3 \beta, \beta$-catenin was significantly upregulated by decreased levels of $G S K-3 \beta$, thus facilitating proliferation potency and suppressing apoptosis in GC cells (56). Additionally, miR-501-5p has been proven to directly target Dickkopf Wnt signaling pathway inhibitor 1 (DKK1), naked cuticle homolog 1 (NKD1), and GSK-3 $\beta$ and suppress their expression, which enhances the stem cell-like phenotype in GC (57).

Wnt ligands, which are involved in a variety of signaling pathways, have been demonstrated to play an active role in mediating the occurrence and progression of several types of human cancers (58). Moreover, the combination of Wnt1 synergistically activates $\mathrm{Wnt} / \beta$-catenin signaling pathway (59). For instance, miR-140-5p suppresses Wnt/ $\beta$-catenin signaling pathway activation by binding to Wnt1 to inhibit GC proliferation and invasion in vitro (60). Similar to miR-140-5p, miR-200b and miR-22 act as tumor suppressors in GC cells by binding to Wnt1. Furthermore, miR-200b and miR-22 synergistically contribute to the efficacy of diallyl disulfide both in vivo and in vitro (61-63). Consistent with these findings, miR-491-5p inhibits progression and induces apoptosis and cell cycle arrest in GC by targeting Wnt3a through the Wnt/ $\beta$-catenin signaling pathway (64).

In addition, miRNAs mediate genes downstream of the Wnt ligand, acting as tumor suppressors in GC. Dishevelled and axin are both downstream genes of the Wnt ligand. 


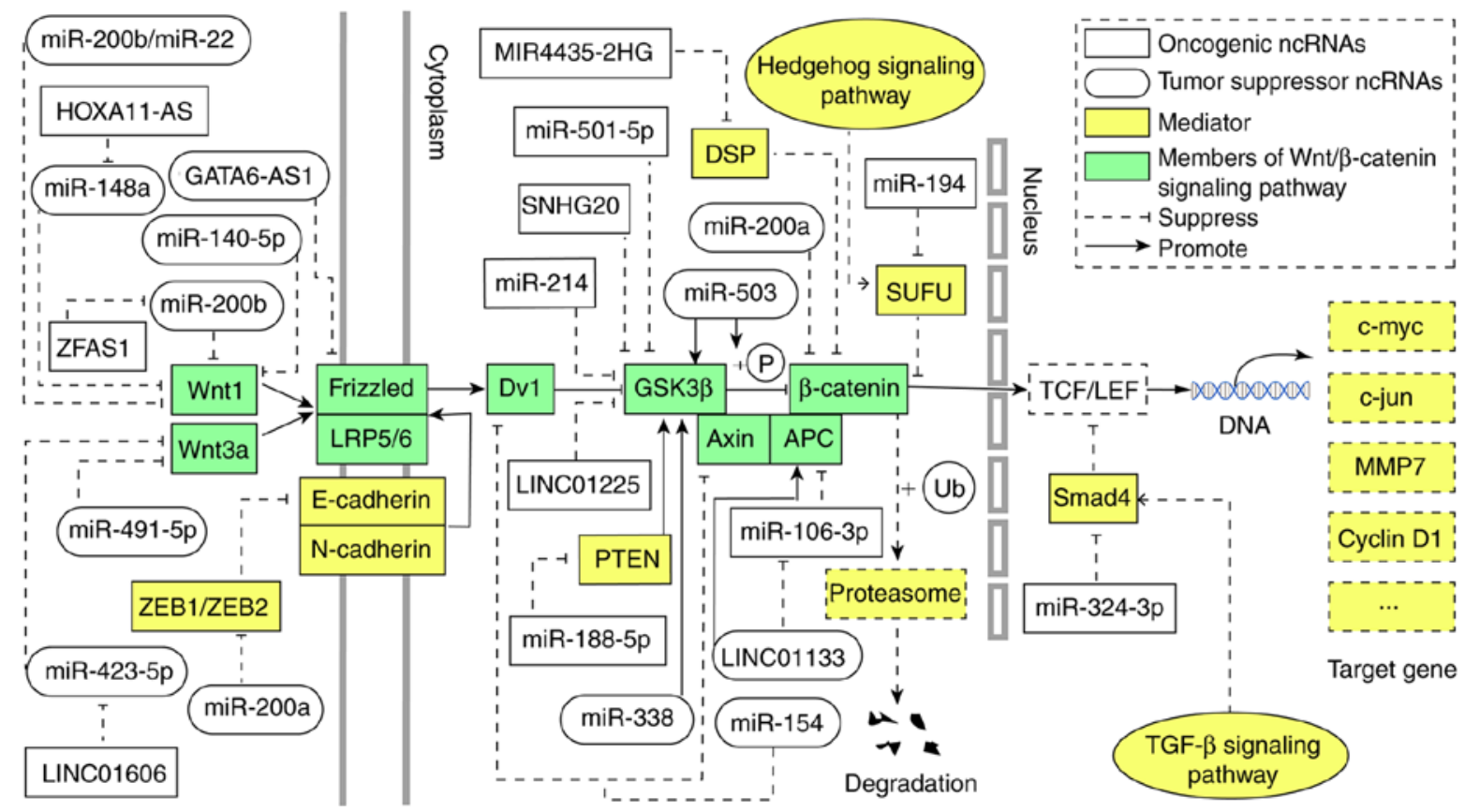

Figure 2. Dual roles of non-coding RNAs (ncRNAs) in modulating the Wnt/ $\beta$-catenin signaling pathway in gastric cancer (GC). ncRNAs directly or indirectly act on members of the Wnt/ $\beta$-catenin signaling pathway to regulate the biological behavior of GC. The biological effect of ncRNAs that act as mediators of the pathway can be reversed. In addition, miRNAs act as tumor suppressors by interacting with pathway mediators, but the specific targets and mechanisms by which they regulate the Wnt/ $\beta$-catenin signaling pathway remain to be elucidated; thus, they are not shown in the figure. Once the signal is activated, the Wnt ligand binds to the Frizzled protein $(\mathrm{Fz})$ receptor and coreceptor lipoprotein receptor-related proteins, causing the adaptor protein Dishevelled (Dvl) to inhibit the destruction complex. This allows $\beta$-catenin to accumulate, be translocated to the nucleus and bind to T-cytokine (TCF)/lymphocyte enhancer-binding factor (LEF) transcription factors to activate expression of target genes, such as c-myc, c-jun, matrix metallopeptidase 7 (MMP7), and cyclin D1.

The Dishevelled-axin domain contains a type of protein named DIXDC1, which is an activator of the Wnt/ $\beta$-catenin signaling pathway. Interestingly, miR-154 can directly inhibit DIXDC1 to suppress the proliferation and invasion of $\mathrm{GC}$ via the $\mathrm{Wnt} / \beta$-catenin signaling pathway (65). Another study revealed that miR-338 decreases c-myc and promotes phosphorylation of GSK-3 $\beta$ to regulate $\mathrm{Wnt} / \beta$-catenin signaling pathway, inhibiting the proliferation, migration, and invasion of GC cells (66). As another inactivator of the Wnt/ $\beta$-catenin signaling pathway, miR-503 is beneficial for inhibiting the progression and invasion of GC through upregulation of GSK-3 $\beta$ and p- $\beta$-catenin (67). The role of ncRNAs in GC was further clarified by Cong et al who discovered that expression of miR-200a is downregulated in gastric carcinoma cells. Furthermore, upregulated miR-200a directly target $\beta$-catenin to suppress activation of the Wnt/ $\beta$-catenin signaling pathway, thus inhibiting tumorigenesis in GC (68).

miRNAs regulate GC by modulating mediators of the Wnt/ $\beta$-catenin signaling pathway. miR-188-5p has been validated as targeting phosphatase and tensin homolog (PTEN), a tumor suppressor involved in a variety of cancers, including GC (69-73). miR-188-5p suppresses PTEN and further promotes phosphorylation of GSK3 $\beta$ to activate the Wnt/ $\beta$-catenin signaling pathway, leading to metastasis and poor prognosis in GC patients (74).

Suppressor of Fused (SUFU), a major negative regulator of the Hedgehog signaling pathway (75-77), as well as the Wnt signaling pathway (78-80), is reported to be abnormally activated in GC (81-83). Oncogenic miR-194 inhibits SUFU; then, massive amounts of $\beta$-catenin accumulate in the cytoplasm, leading to translocation of $\beta$-catenin to the nucleus, which promotes GC carcinogenesis $(84,85)$.

Consistently, miR-324-3p activates Wnt/ $\beta$-catenin signaling pathway by inhibiting expression of the Wnt/ $\beta$-catenin signaling pathway antagonist SMAD family member 4 (Smad4) to promote tumorigenesis and inhibit apoptosis in GC cells. Such increased expression of miR-324-3p is accompanied by the expansion and increased proliferation rate of gastric organoids (86).

miRNAs can also act as inhibitors of the Wnt/ $\beta$-catenin signaling pathway by targeting its mediators. Overexpression of miR-200a upregulates expression of E-cadherin by targeting zinc finger E-box-binding homeobox 1 (ZEB1) and zinc finger E-box binding homeobox 2 (ZEB2), which transfers $\beta$-catenin from the nucleus to the cytoplasm, suppressing activation of the pathway (68). Furthermore, miR-219-5p targets liver receptor homolog-1 (LRH-1) to inhibit Wnt/ $\beta$-catenin signaling pathway, further suppressing the proliferation, migration, and invasion of GC (87).

Moreover, miR-302b inhibits expression of cyclin D1 and c-myc by targeting erythropoietin-producing hepatocellular (Eph) A2 via the Wnt/ $\beta$-catenin signaling pathway (88). Consistently, the level of miR-19 in GC clinical samples is significantly decreased compared with that noted in normal gastric tissue. Further analysis revealed that the transcription factor myocyte enhancer factor 2D (MEF2D) functions as a potential target of miR-19. Indeed, high expression of MEF2D promotes activation of the Wnt/ $\beta$-catenin signaling 


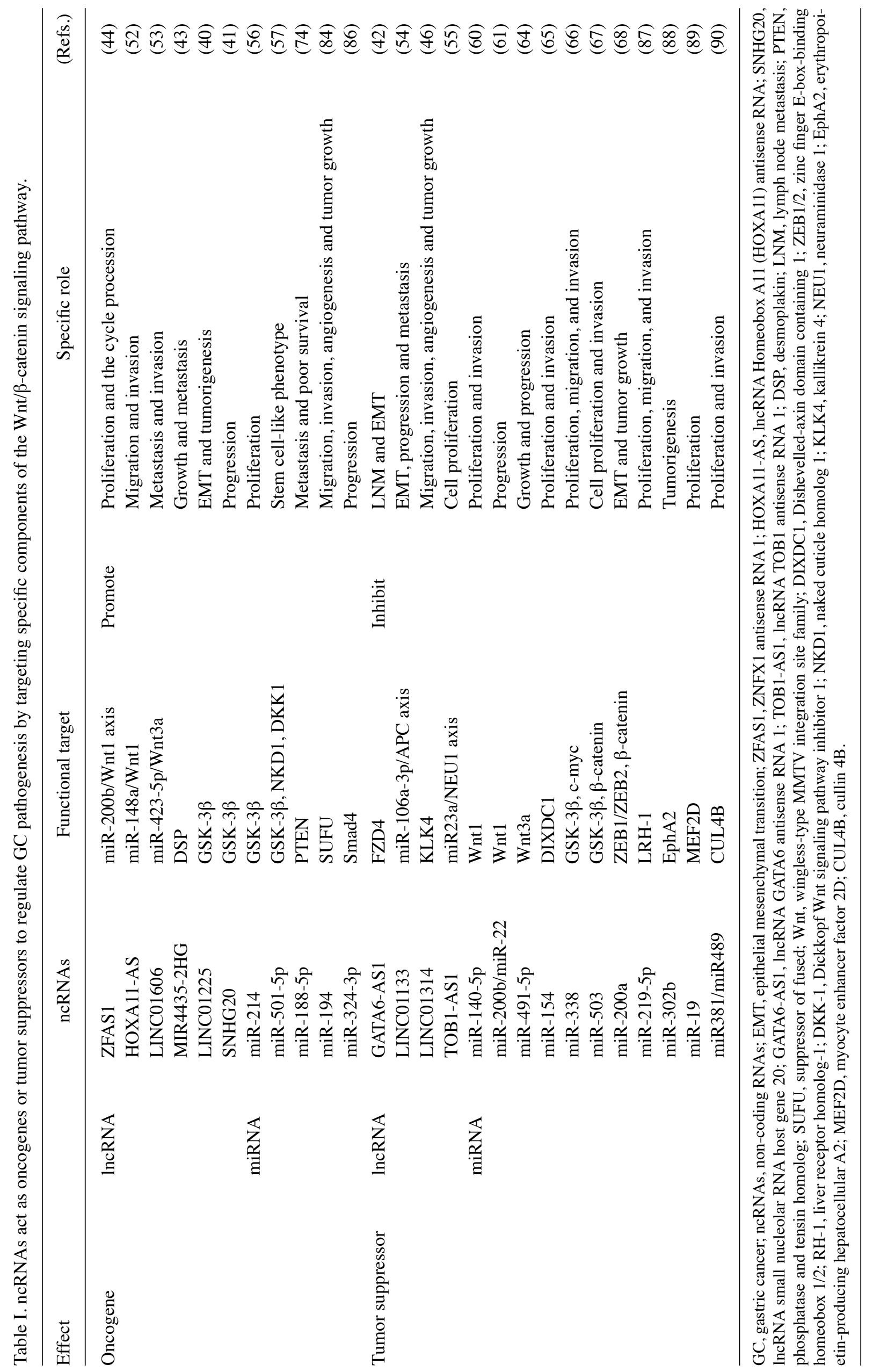


pathway and contributes to the tumorigenesis and growth of GC. However, such effects of MEF2D can be reversed by miR-19 (89). Additionally, synergistic upregulation of miR381 and miR489 exerts phenotypic effects such as inhibiting cell migration, invasion and EMT through inactivation of the Wnt/ $\beta$-catenin signaling pathway by directly targeting cullin 4B (CUL4B) (90).

As mentioned above, ncRNAs can serve as underlying novel biomarkers and therapeutic targets in human GC diagnosis and treatment. Thus, efforts to thoroughly understand the role of ncRNAs in modulating the $\mathrm{Wnt} / \beta$-catenin signaling pathway in GC is crucial (Fig. 2).

\section{Conclusions and perspectives}

GC is still a global concern and a great threat to humans (91). Despite tremendous effort in recent decades to elucidate the role of ncRNAs and the Wnt/ $\beta$-catenin signaling pathway in the initiation and progression of GC, the specific molecular mechanism remains unclear. This review summarizes recent studies on the role of ncRNAs in modulating the Wnt/ $\beta$-catenin signaling pathway (Table I). These findings support the hypothesis that modulation by ncRNAs can promote or inhibit downstream Wnt/ $\beta$-catenin signaling pathway in GC.

Various ncRNAs contribute to target directly or indirectly the members of the Wnt/ $\beta$-catenin signaling pathway in GC. It remains unknown whether some microRNAs that interacts with lncRNAs are involved in this regulatory process. Interestingly, some substances that act as mediators of the ncRNAs are also regulators of other signaling pathways. It means further study is needed to explore whether the lncRNA-Wnt/ $\beta$-catenin signaling pathway is the main signaling pathway affecting the progression of GC.

In addition, compared with that in normal gastric tissue, expression of ncRNAs is abnormal in GC tissue and cells; hence, detecting changes in ncRNA expression may serve as a diagnostic factor in the early stage of GC. In addition, ncRNAs directly or indirectly act on members of the $\mathrm{Wnt} / \beta$-catenin signaling pathway to regulate the biological behavior of GC, and EMT, angiogenesis and other pathogenic processes that may be involved in GC can serve as effective entry points for GC research. Thus, determining specific targets is paramount, and the development of targeted drugs, improvement in the accuracy of targeted drugs and reduction in drug resistance rates will offer a glimmer of hope to patients with GC. We firmly believe that a better understanding of the precise underlying molecular mechanisms will increase our knowledge of the basic mechanism of GC and provide new clues to developing valuable diagnostic and therapeutic strategies for GC.

\section{Acknowledgements}

Not applicable.

\section{Funding}

The present study was supported by grants from the Educational Department of Jiangxi Province, China (no. GJJ20053).

\section{Availability of data and materials}

The data used to support the findings of this study are available from the corresponding author upon request. All information reported in this Review is based on relevant and current references.

\section{Authors' contributions}

ZS, DG, LC, WD and QY were all involved in selection of the review topic, literature data search, writing, figure and table design, and editing of the manuscript.

\section{Ethics approval and consent to participate}

Not applicable.

\section{Patient consent for publication}

Not applicable.

\section{Competing interests}

The authors declare that they have no competing interests.

\section{References}

1. Catalano V, Labianca R, Beretta GD, Gatta G, de Braud F and Van Cutsem E: Gastric cancer. Crit Rev Oncol Hematol 71: 127-164, 2009.

2. Bray F, Ferlay J, Soerjomataram I, Siegel RL, Torre LA and Jemal A: Global cancer statistics 2018: GLOBOCAN estimates of incidence and mortality worldwide for 36 cancers in 185 countries. CA Cancer J Clin 68: 394-424, 2018.

3. Balakrishnan M, George R, Sharma A and Graham DY: Changing trends in stomach cancer throughout the world. Curr Gastroenterol Rep 19: 36, 2017.

4. Chen W, Zheng R, Baade PD, Zhang S, Zeng H, Bray F, Jemal A $\mathrm{Yu}$ XQ and He J: Cancer statistics in China, 2015. CA Cancer J Clin 66: 115-132, 2016.

5. Thiel A and Ristimäki A: Gastric cancer: Basic aspects. Helicobacter 17 (Suppl 1): S26-S29, 2012.

6. Tian L, Zhao Z, Xie L and Zhu J: miR-361-5p inhibits the mobility of gastric cancer cells through suppressing epithelial-mesenchymal transition via the Wnt/ $\beta$-catenin pathway. Gene 675: 102-109, 2018.

7. Xie SS, Jin J, Xu X, Zhuo W and Zhou TH: Emerging roles of non-coding RNAs in gastric cancer: Pathogenesis and clinical implications. World J Gastroenterol 22: 1213-1223, 2016.

8. Zhang $\mathrm{M}$ and $\mathrm{Du} \mathrm{X}$ : Noncoding RNAs in gastric cancer: Research progress and prospects. World J Gastroenterol 22: 6610-6618, 2016.

9. Zhang S, Chen L, Cui B, Chuang HY, Yu J, Wang-Rodriguez J, Tang L, Chen G, Basak GW and Kipps TJ: ROR1 is expressed in human breast cancer and associated with enhanced tumor-cell growth. PLoS One 7: e31127, 2012.

10. O'Brien CA, Pollett A, Gallinger S and Dick JE: A human colon cancer cell capable of initiating tumour growth in immunodeficient mice. Nature 445: 106-110, 2007.

11. Ma S, Chan KW, Hu L, Lee TK, Wo JY, Ng IO, Zheng BJ and Guan XY: Identification and characterization of tumorigenic liver cancer stem/progenitor cells. Gastroenterology 132: 2542-2556, 2007.

12. Nagy TA, Wroblewski LE, Wang D, Piazuelo MB, Delgado A, Romero-Gallo J, Noto J, Israel DA, Ogden SR, Correa P, et al: $\beta$-catenin and 120 mediate PPAR $\delta$-dependent proliferation induced by Helicobacter pylori in human and rodent epithelia. Gastroenterology 141: 553-564, 2011.

13. Ahn HJ and Lee DS: Helicobacter pylori in gastric carcinogenesis. World J Gastrointest Oncol 7: 455-465, 2015. 
14. Valenzuela MA, Canales J, Corvalán AH and Quest AF: Helicobacter pylori-induced inflammation and epigenetic changes during gastric carcinogenesis. World J Gastroenterol 21: 12742-12756, 2015.

15. Baker NE: Molecular cloning of sequences from wingless, a segment polarity gene in Drosophila: The spatial distribution of a transcript in embryos. EMBO J 6: 1765-1773, 1987.

16. Baker NE: Transcription of the segment-polarity gene wingless in the imaginal discs of Drosophila, and the phenotype of a pupal-lethal wg mutation. Development 102: 489-497, 1988.

17. Peifer $\mathrm{M}$ and Wieschaus E: The segment polarity gene armadillo encodes a functionally modular protein that is the Drosophila homolog of human plakoglobin. Cell 63: 1167-1176, 1990.

18. Phillips RG, Roberts IJ, Ingham PW and Whittle JR: The Drosophila segment polarity gene patched is involved in a position-signalling mechanism in imaginal discs. Development 110: 105-114, 1990.

19. Therond P, Busson D, Guillemet E, Limbourg-Bouchon B Preat T, Terracol R, Tricoire H and Lamour-Isnard C: Molecular organisation and expression pattern of the segment polarity gene fused of Drosophila melanogaster. Mech Dev 44: 65-80, 1993.

20. Semenov MV, Habas R, Macdonald BT and He X: SnapShot: Noncanonical Wnt signaling pathways. Cell 131: 1378, 2007.

21. MacDonald BT, Tamai K and He X: Wnt/beta-catenin signaling: Components, mechanisms, and diseases. Dev Cell 17: 9-26, 2009.

22. Nusse $\mathrm{R}$ and Clevers $\mathrm{H}$ : Wnt/ $\beta$-catenin signaling, disease, and emerging therapeutic modalities. Cell 169: 985-999, 2017.

23. Rao TP and Kühl M: An updated overview on Wnt signaling pathways: A prelude for more. Circ Res 106: 1798-1806, 2010.

24. Schulte G: International union of basic and clinical pharmacology. LXXX. The class Frizzled receptors. Pharmacol Rev 62: 632-667, 2010.

25. Shang $\mathrm{S}$, Hua F and $\mathrm{Hu} \mathrm{ZW}$ : The regulation of $\beta$-catenin activity and function in cancer: Therapeutic opportunities. Oncotarget 8 : 33972-33989, 2017.

26. Duchartre Y, Kim YM and Kahn M: The Wnt signaling pathway in cancer. Crit Rev Oncol Hematol 99: 141-149, 2016.

27. Zhan T, Rindtorff $\mathrm{N}$ and Boutros $\mathrm{M}$ : Wnt signaling in cancer. Oncogene 36: 1461-1473, 2017

28. Sato N, Meijer L, Skaltsounis L, Greengard P and Brivanlou AH: Maintenance of pluripotency in human and mouse embryonic stem cells through activation of Wnt signaling by a pharmacological GSK-3-specific inhibitor. Nat Med 10: 55-63, 2004.

29. Ooi CH, Ivanova T, Wu J, Lee M, Tan IB, Tao J, Ward L, Koo JH, Gopalakrishnan V, Zhu Y, et al: Oncogenic pathway combinations predict clinical prognosis in gastric cancer. PLoS Genet 5: e1000676, 2009

30. Gomes AQ, Nolasco S and Soares H: Non-coding RNAs: Multi-tasking molecules in the cell. Int J Mol Sci 14: 16010-16039, 2013.

31. Li PF, Chen SC, Xia T, Jiang XM, Shao YF, Xiao BX and Guo JM: Non-coding RNAs and gastric cancer. World J Gastroenterol 20: 5411-5419, 2014

32. Taft RJ, Pang KC, Mercer TR, Dinger M and Mattick JS Non-coding RNAs: Regulators of disease. J Pathol 220: 126-139, 2010.

33. Qiu MT, Hu JW, Yin R and Xu L: Long noncoding RNA: An emerging paradigm of cancer research. Tumour Biol 34: 613-620, 2013.

34. Lin F, Li Y, Yan S, Liu S, Qian W, Shen D, Lin Q and Mao W: MicroRNA-181a inhibits tumor proliferation, invasiveness, and metastasis and is downregulated in gastric cancer. Oncol Res 22 75-84, 2015.

35. Shin VY and Chu KM: miRNA as potential biomarkers and therapeutic targets for gastric cancer. World J Gastroenterol 20 : 10432-10439, 2014.

36. Jiang C, Chen X, Alattar M, Wei J and Liu H: MicroRNAs in tumorigenesis, metastasis, diagnosis and prognosis of gastric cancer. Cancer Gene Ther 22: 291-301, 2015.

37. Chen S, Zhu J, Yu F, Tian Y, Ma S and Liu X: Combination of miRNA and RNA functions as potential biomarkers for gastric cancer. Tumour Biol 36: 9909-9918, 2015.

38. Miyashita K, Nakada M, Shakoori A, Ishigaki Y, Shimasaki T, Motoo Y, Kawakami K and Minamoto T: An emerging strategy for cancer treatment targeting aberrant glycogen synthase kinase 3 beta. Anticancer Agents Med Chem 9: 1114-1122, 2009.
39. Sahin I, Eturi A, De Souza A, Pamarthy S, Tavora F, Giles FJ and Carneiro BA: Glycogen synthase kinase-3 beta inhibitors as novel cancer treatments and modulators of antitumor immune responses. Cancer Biol Ther 20: 1047-1056, 2019.

40. Xu Y, Zhang G, Zou C, Qi W, Gong Z, Zhang G, Ma G, Zhang W and Jiang P: Long non-coding RNA LINC01225 promotes proliferation, invasion and migration of gastric cancer via Wnt/ $\beta$-catenin signalling pathway. J Cell Mol Med 23: 7581-7591, 2019.

41. Liu J, Liu L, Wan JX and Song Y: Long noncoding RNA SNHG20 promotes gastric cancer progression by inhibiting p21 expression and regulating the GSK-3 $\beta / \beta$-catenin signaling pathway. Oncotarget 8: 80700-80708, 2017.

42. Li ZT, Zhang X, Wang DW, Xu J, Kou KJ, Wang ZW, Yong G, Liang DS and Sun XY: Overexpressed lncRNA GATA6-AS1 inhibits LNM and EMT via FZD4 through the Wnt/ $\beta$-catenin signaling pathway in GC. Mol Ther Nucleic Acids 19: 827-840, 2020.

43. Wang H, Wu M, Lu Y,He K, Cai X, Yu X, Lu J and Teng L: IncRNA MIR4435-2HG targets desmoplakin and promotes growth and metastasis of gastric cancer by activating Wnt/ $\beta$-catenin signaling. Aging (Albany NY) 11: 6657-6673, 2019.

44. Zhang F, Li Y, Xu W, He L, Tan Y and Xu H: Long non-coding RNA ZFAS1 regulates the malignant progression of gastric cancer via the microRNA-200b-3p/Wnt1 axis. Biosci Biotechnol Biochem 83: 1289-1299, 2019.

45. Wu X, Zhang P, Zhu H, Li S, Chen X and Shi L: Long noncoding RNA FEZF1-AS1 indicates a poor prognosis of gastric cancer and promotes tumorigenesis via activation of Wnt signaling pathway. Biomed Pharmacother 96: 1103-1108, 2017.

46. Tang L, Wen JB, Wen P, Li X, Gong M and Li Q: Long non-coding RNA LINC01314 represses cell migration, invasion, and angiogenesis in gastric cancer via the $\mathrm{Wnt} / \beta$-catenin signaling pathway by down-regulating KLK4. Cancer Cell Int 19: 94, 2019.

47. Gu W, Ren JH, Zheng X, Hu XY and Hu MJ: Comprehensive analysis of expression profiles of long non-coding RNAs with associated ceRNA network involved in gastric cancer progression. Mol Med Rep 20: 2209-2218, 2019.

48. Qi X, Zhang DH, Wu N, Xiao JH, Wang X and Ma W: ceRNA in cancer: Possible functions and clinical implications. J Med Genet 52: 710-718, 2015 .

49. Liu Y, Zhu J, Ma X, Han S, Xiao D, Jia Y and Wang Y: ceRNA network construction and comparison of gastric cancer with or without Helicobacter pylori infection. J Cell Physiol 234: 7128-7140, 2019.

50. Karreth FA and Pandolfi PP: ceRNA cross-talk in cancer: When ce-bling rivalries go awry. Cancer Discov 3: 1113-1121, 2013.

51. Xu J, Li Y, Lu J, Pan T, Ding N, Wang Z, Shao T, Zhang J, Wang L and Li X: The mRNA related ceRNA-ceRNA landscape and significance across 20 major cancer types. Nucleic Acids Res 43: 8169-8182, 2015.

52. Guo T, Yuan X, Liu DF, Peng SH and Xu AM: lncRNA HOXA11-AS promotes migration and invasion through modulating miR-148a/WNT1/ $\beta$-catenin pathway in gastric cancer. Neoplasma 67: 492-500, 2020.

53. Luo Y, Tan W, Jia W, Liu Z, Ye P, Fu Z, Lu F, Xiang W, Tang L, Yao L, et al: The long non-coding RNA LINC01606 contributes to the metastasis and invasion of human gastric cancer and is associated with Wnt $/ \beta$-catenin signaling. Int J Biochem Cell Biol 103: 125-134, 2018.

54. Yang XZ, Cheng TT, He QJ, Lei ZY, Chi J, Tang Z, Liao QX, Zhang H, Zeng LS and Cui SZ: LINC01133 as ceRNA inhibits gastric cancer progression by sponging miR-106a-3p to regulate APC expression and the Wnt/ $\beta$-catenin pathway. Mol Cancer 17: 126,2018

55. Jiang K, Zhi XH, Ma YY and Zhou LQ: Long non-coding RNA TOB1-AS1 modulates cell proliferation, apoptosis, migration and invasion through miR-23a/NEU1 axis via Wnt/ $\beta$-catenin pathway in gastric cancer. Eur Rev Med Pharmacol Sci 23 9890-9899, 2019

56. Li HL, Liang S, Cui JH and Han GY: Targeting of GSK-3 $\beta$ by miR-214 to facilitate gastric cancer cell proliferation and decrease of cell apoptosis. Eur Rev Med Pharmacol Sci 22: 127-134, 2018.

57. Fan D, Ren B, Yang X, Liu J and Zhang Z: Upregulation of miR-501-5p activates the wnt/ $\beta$-catenin signaling pathway and enhances stem cell-like phenotype in gastric cancer. J Exp Clin Cancer Res 35: 177, 2016.

58. Willert K and Nusse R: Wnt proteins. Cold Spring Harb Perspect Biol 4: a007864, 2012. 
59. Alok A, Lei Z, Jagannathan NS, Kaur S, Harmston N, Rozen SG, Tucker-Kellogg L and Virshup DM: Wnt proteins synergize to activate $\beta$-catenin signaling. J Cell Sci 130: 1532-1544, 2017.

60. Cha Y, He Y, Ouyang K, Xiong H, Li J and Yuan X: MicroRNA-140-5p suppresses cell proliferation and invasion in gastric cancer by targeting WNT1 in the WNT/ $\beta$-catenin signaling pathway. Oncol Lett 16: 6369-6376, 2018.

61. Tang H, Kong Y, Guo J, Tang Y, Xie X, Yang L, Su Q and Xie X: Diallyl disulfide suppresses proliferation and induces apoptosis in human gastric cancer through Wnt-1 signaling pathway by up-regulation of miR-200b and miR-22. Cancer Lett 340: 72-81, 2013.

62. Su B, Su J, Zeng Y, Ding E, Liu F, Tan T, Xia H, Wu YH Zeng X, Ling H, et al: Diallyl disulfide inhibits TGF- $\beta 1$-induced upregulation of Rac1 and $\beta$-catenin in epithelial-mesenchymal transition and tumor growth of gastric cancer. Oncol Rep 39: 2797-2806, 2018

63. Xiang SL, Xiao XL, Ling H, Liao QJ, Zhou XT, Dong L and Su Q: Antitumor effect of diallyl disulfide on human gastric cancer MGC803 cells xenograft in nude mice. Ai Zheng 24: 940-944, 2005 (In Chinese).

64. Sun R, Liu Z, Tong D, Yang Y, Guo B, Wang X, Zhao L and Huang C: miR-491-5p, mediated by Foxi1, functions as a tumor suppressor by targeting Wnt3a/ $/$-catenin signaling in the development of gastric cancer. Cell Death Dis 8: e2714, 2017.

65. Song J, Guan Z, Li M, Sha S, Song C, Gao Z and Zhao Y: MicroRNA-154 inhibits the growth and invasion of gastric cancer cells by targeting DIXDC1/WNT signaling. Oncol Res 26: 847-856, 2018.

66. Song B, Lin HX, Dong LL, Ma JJ and Jiang ZG: MicroRNA-338 inhibits proliferation, migration, and invasion of gastric cancer cells by the Wnt/ $\beta$-catenin signaling pathway. Eur Rev Med Pharmacol Sci 22: 1290-1296, 2018.

67. Li W, Li J, Mu H, Guo M and Deng H: miR-503 suppresses cell proliferation and invasion of gastric cancer by targeting HMGA2 and inactivating WNT signaling pathway. Cancer Cell Int 19: $164,2019$.

68. Cong N, Du P, Zhang A, Shen F, Su J, Pu P, Wang T, Zjang J, Kang $C$ and Zhang Q: Downregulated microRNA-200a promotes EMT and tumor growth through the wnt $/ \beta$-catenin pathway by targeting the E-cadherin repressors ZEB1/ZEB2 in gastric adenocarcinoma. Oncol Rep 29: 1579-1587, 2013.

69. Conde-Perez A, Gros G, Longvert C, Pedersen M, Petit V, Aktary Z, Viros A, Gesbert F, Delmas V, Rambow F, et al: A caveolin-dependent and PI3K/AKT-independent role of PTEN in $\beta$-catenin transcriptional activity. Nat Commun 6: 8093, 2015

70. de Araujo WM, Robbs BK, Bastos LG, de Souza WF, Vidal FC, Viola JP and Morgado-Diaz JA: PTEN overexpression cooperates with lithium to reduce the malignancy and to increase cell death by apoptosis via PI3K/Akt suppression in colorectal cancer cells. J Cell Biochem 117: 458-469, 2016.

71. Jang $\mathrm{H}$, Lee $\mathrm{OH}$, Lee $\mathrm{Y}$, Yoon H, Chang EM, Park M, Lee JW, Hong K, Kim JO, Kim NK, et al: Melatonin prevents cisplatin-induced primordial follicle loss via suppression of PTEN/AKT/FOXO3a pathway activation in the mouse ovary. J Pineal Res 60: 336-347, 2016.

72. Perumal E, So Youn K, Sun S, Seung-Hyun J, Suji M, Jieying L and Yeun-Jun C: PTEN inactivation induces epithelial-mesenchymal transition and metastasis by intranuclear translocation of $\beta$-catenin and snail/slug in non-small cell lung carcinoma cells. Lung Cancer 130: 25-34, 2019.

73. Ma J, Guo X, Zhang J, Wu D, Hu X, Li J, Lan Q, Liu Y and Dong W: PTEN gene induces cell invasion and migration via regulating AKT/GSK-3 $\beta / \beta$-catenin signaling pathway in human gastric cancer. Dig Dis Sci 62: 3415-3425, 2017.
74. Li Y, Yan X, Shi J, He Y, Xu J, Lin L, Chen W, Lin X and Lin X: Aberrantly expressed miR-188-5p promotes gastric cancer metastasis by activating $\mathrm{Wnt} / \beta$-catenin signaling. BMC Cancer 19: 505, 2019.

75. Katoh $\mathrm{Y}$ and Katoh M: Hedgehog signaling pathway and gastrointestinal stem cell signaling network (Review). Int J Mol Med 18: 1019-1023, 2006.

76. Katoh Y and Katoh M: Hedgehog target genes: Mechanisms of carcinogenesis induced by aberrant hedgehog signaling activation. Curr Mol Med 9: 873-886, 2009.

77. Katoh M: Genomic testing, tumor microenvironment and targeted therapy of hedgehog-related human cancers. Clin Sci (Lond) 133: 953-970, 2019.

78. Maniatis T: A ubiquitin ligase complex essential for the NF-kappaB, Wnt/Wingless, and hedgehog signaling pathways. Genes Dev 13: 505-510, 1999.

79. Min TH, Kriebel M, Hou S and Pera EM: The dual regulator Sufu integrates hedgehog and Wnt signals in the early xenopus embryo. Dev Biol 358: 262-276, 2011.

80. Taylor MD, Zhang X, Liu L, Hui CC, Mainprize TG, Scherer SW, Wainwright B, Hogg D and Rutka JT: Failure of a medulloblastoma-derived mutant of SUFU to suppress WNT signaling. Oncogene 23: 4577-4583, 2004

81. Yang L, Huang S, Bian Y, Ma X,Zhang H and Xie J: Identification of signature genes for detecting hedgehog signaling activation in gastric cancer. Mol Med Rep 3: 473-478, 2010.

82. Yan R, Peng X, Yuan X, Huang D, Chen J, Lu Q, Lv N and Luo S: Suppression of growth and migration by blocking the hedgehog signaling pathway in gastric cancer cells. Cell Oncol (Dordr) 36 421-435, 2013.

83. Katoh Y and Katoh M: Hedgehog signaling pathway and gastric cancer. Cancer Biol Ther 4: 1050-1054, 2005.

84. Peng Y,Zhang X, Ma Q, Yan R, Qin Y, Zhao Y, Cheng Y, Yang M, Wang Q, Feng X, et al: miRNA-194 activates the Wnt/ $\beta$-catenin signaling pathway in gastric cancer by targeting the negative Wnt regulator, SUFU. Cancer Lett 385: 117-127, 2017.

85. Peng Y, Zhang X, Lin H, Deng S, Huang Y, Qin Y, Feng X, Yan R, Zhao Y, Cheng Y, et al: Inhibition of miR-194 suppresses the Wnt/ $\beta$-catenin signalling pathway in gastric cancer. Oncol Rep 40: 3323-3334, 2018.

86. Sun GL, Li Z, Wang WZ, Chen Z, Zhang L, Li Q, Wei S, Li BW, $\mathrm{Xu} \mathrm{JH}$, Chen L, et al: miR-324-3p promotes gastric cancer development by activating Smad4-mediated Wnt/beta-catenin signaling pathway. J Gastroenterol 53: 725-739, 2018.

87. Li C, Dong J, Han Z and Zhang K: MicroRNA-219-5p represses the proliferation, migration, and invasion of gastric cancer cells by targeting the LRH-1/Wnt//-catenin signaling pathway. Oncol Res 25: 617-627, 2017.

88. Huang J, He Y, Mcleod HL, Xie Y, Xiao D, Hu H, Chen P, Shen L, Zeng S, Yin X, et al: miR-302b inhibits tumorigenesis by targeting EphA2 via Wnt/ $\beta$-catenin/EMT signaling cascade in gastric cancer. BMC Cancer 17: 886, 2017.

89. $\mathrm{Xu} \mathrm{K}$ and Zhao YC: MEF2D/Wnt/ $\beta$-catenin pathway regulates the proliferation of gastric cancer cells and is regulated by microRNA-19. Tumour Biol 37: 9059-9069, 2016

90. Fang Z, Zhong M, Wang Y, Yuan X, Guo H, Yao Y, Feng M, Chen J, Xiong J and Xiang X: miR-381 and miR-489 suppress cell proliferation and invasion by targeting CUL4B via the $\mathrm{Wnt} / \beta$-catenin pathway in gastric cancer. Int J Oncol 54: 733-743, 2019.

91. Arnold M, Park JY, Camargo MC, Lunet N, Forman D and Soerjomataram I: Is gastric cancer becoming a rare disease? A global assessment of predicted incidence trends to 2035 . Gut 69: 823-829, 2020. 